\title{
Aplikasi Monitoring Keamanan Ruangan Menggunakan IP Camera Berbasis Android
}

\author{
Sri Apriyani ${ }^{1}$, Ridho Taufiq Subagio ${ }^{2}$, Wanda Ilham $^{3}$ \\ Teknik Informatika, Universitas Catur Insan Cendekia \\ Jl.Kesambi No. 202 Kota Cirebon, Indonesia \\ 11apriyani.sry@gmail.com, ${ }^{2}$ ridho.taufiq@cic.ac.id, ${ }^{3}$ wandailham@cic.ac.id
}

Diterima : 26 Agustus 2020

Disetujui : 28 September 2020

\begin{abstract}
Abstrak - Dengan maraknya teknologi internet dalam dunia pendidikan, hampir semua kegiatan di semua instansi pendidikan dapat dilakukan secara online, serta dilakukan kapan dan dimana saja. Salah satu pemanfaatan teknologi internet tersebut adalah monitoring keamanan ruangan pada suatu Perguruan Tinggi. Pada Universitas Catur Insan Cendekia (CIC) monitoring keamanan ruangan masih menggunakan CCTV (Closed Circuit Television) analog yang dihubungkan langsung dengan DVR (Digital Video Recorder) jika jumlah port DVR tidak memenuhi jumlah kamera yang akan digunakan maka harus menyediakan DVR yang baru serta untuk melihat hasil rekaman CCTV harus memasuki ruangan yang terpasang DVR, hal tersebut menjadi tidak efesien karena Universitas CIC menerapkan konsep kerja Work From Home (WFH) yang membuat bagian keamanan tidak selalu berada di ruang keamanan tersebut. Adapun tujuan penelitian ini adalah merancang dan membangun sistem monitoring keamanan ruangan menggunakan IP Camera berbasis Android. Metode pengembangan perangkat lunak yang digunakan adalah SDLC model waterfall yang terdiri dari 5 tahapan yaitu analisis, desain, pengkodean, pengujian dan pemeliharaan. Setelah semua tahapan penelitian telah dilakukan, hasil penelitian ini adalah aplikasi monitoring keamanan ruangan dengan IP Camera pada Universitas CIC yang dapat memudahkan petugas keamanan ruangan dalam memantau keamanan ruangan melalui aplikasi pada smartphone Android.
\end{abstract}

Kata Kunci : Monitoring ruangan, IP Camera, Android, Universitas CIC.

\section{PENDAHULUAN}

Keamanan merupakan aspek penting yang tidak bisa lepas dari kehidupan sehari-hari, banyak masalah keamanan yang timbul baik pada perusahaan, perguruan tinggi, bahkan rumah pribadi. Masalah-masalah tersebut dapat berupa pencurian atau perampokan. Salah satu cara untuk mengatasi masalah tersebut adalah membuat sistem pengawasan jarak jauh yang bisa dilakukan dengan menggunakan kamera pemantau.

Saat ini sistem keamanan yang ada di Universitas Catur Insan Cendekia kurang efesien baik dalam penggunaan perangkat keras yang digunakan atau informasi yang akan didapatkan karena masih menggunakan CCTV analog yang dihubungkan langsung dengan DVR sehingga kurang efesien jika jumlah port DVR tidak memenuhi jumlah kamera yang akan digunakan maka harus menyediakan DVR yang baru. Dalam monitoring ruangan pun CCTV diletakan dalam 1 ruang yang terpusat. Hal tersebut menjadi tidak efesien dikarenakan Universitas CIC menerapkan konsep kerja Work From Home yang membuat Petugas tidak selalu berada dikampus. Sehingga diperlukan sistem untuk mengakses CCTV dimanapun dan kapanpun.

Sistem yang baik adalah sistem yang mampu menghasilkan informasi yang relevan dan tepat waktu, sistem harus dapat meminimalisir biaya serta sederhana dalam operasinya. Dari hal tersebut dibutuhkan sebuah sistem keamanan yang dapat mengurangi 
penggunaan perangkat keras salah satunya yaitu perangkat lunak gratis seperti aplikasi Shinobi.

Aplikasi Shinobi merupakan sebuah aplikasi berbasis web yang digunakan untuk recording video CCTV atau IP Camera yang bersifat Open Source, dan dirancang menggunakan bahasa pemograman Node.js. Jika selama ini kita mengenal JavaScript sebagai bahasa pemrograman yang berjalan di sisi client/browser saja, maka Node.js ada untuk melengkapi peran JavaScript sehingga dapat berjalan sebagai bahasa pemrograman di sisi server [1]. Shinobi menyediakan beberapa API (Applications Programming Interface) untuk dikembangkan ke berbagai platform, salah satunya Android. API adalah sebuah interface yang memiliki set fungsi untuk bisa mengakses aplikasi lain, sehingga bisa menggunakan fitur pada aplikasi tersebut tanpa membuat ulang.[2]

Pada penulisan ini akan dirancang dan dibuat sebuah aplikasi monitoring ruangan berbasis Android dengan memanfaatkan API yang disediakan oleh aplikasi Shinobi.

\section{A. Penelitian Terkait}

II. TINJAUAN PUSTAKA

Beberapa penelitian yang berkaitan dengan perancangan aplikasi monitoring ruangan yaitu pada penelitian [3], ada 4 tahap metode yang digunakan yaitu wawancara, studi pustaka, perancangan aplikasi, serta implementasi dan pengevaluasian aplikasi, penelitian ini menghasilkan sebuah aplikasi pemantau ruangan untuk perangkat mobile berbasis Android dengan menggunakan koneksi internet seperti wi-fi atau layanan data seluler. Selanjutnya pada penelitian [4], menghasilkan sebuah sistem jaringan agar CCTV bisa diakses secara online, pada penelitian ini metode yang digunakan yaitu dengan mempelajari sistem yang sedang berjalan kemudian merancang sistem yang diusulkan. Selanjutnya pada penelitian [5] berdasarkan hasil perhitungan kuesioner yang didapatkan dari dosen dan mahasiswa bahwa pemantauan terhadap kondisi dalam sebuah ruangan dan menyimpan histori aktifitas yang terjadi yang dapat diakses secara jarak jauh dapat membantu meningkatkan keamanan ruangan dan penerimaan informasi yang lebih cepat. Hasil dari penelitian ini adalah aplikasi remote view Camera CCTV, dimana keadaan real laboratorium ditampilkan secara langsung kehandphone.

\section{B. IP Camera}

IP Camera atau biasa disebut dengan Netcam merupakan suatu perangkat untuk mengambil gambar dan rekaman sebuah benda yang memiliki kemampuan dalam memproses pengelihatan dan audio yang dapat diakses melalui PC secara langsung, LAN internet, dan layanan data seluler. [6]

\section{Cara Kerja IP Camera}

Untuk mempermudah memahami cara kerja IP Camera berikut ini diperlihatkan blok diagramnya.

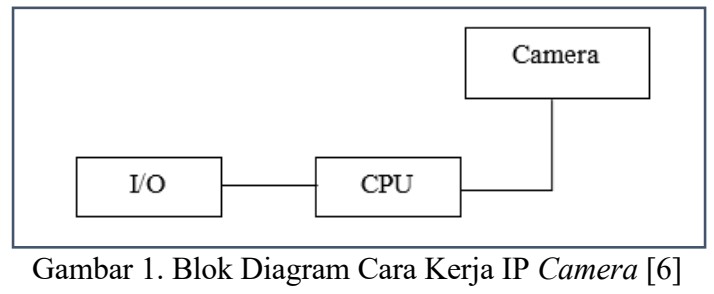

Pada Gambar 1. Diperlihatkan blok diagram sebuah IP Camera. Ketika IP Camera beroperasi untuk meng-capture object berupa manusia, hewan, dan benda lainnya melalui lensa kamera, lensa akan mengubah object yang di-capture menjadi sinyal listrik. Sinyal tersebut kemudian diteruskan ke bagian CPU untuk diproses agar mudah dilewatkan pada jaringan IP. Kemudian, diteruskan ke bagian I/O yang telah berbentuk paket-paket data, kemudian dikeluarkan melalui port RJ 45 untuk diteruskan ke tujuan langsung, yaitu monitor PC atau media display lainnya [6].

\section{RTSP (Real Time Streaming Protocol)}

RTSP merupakan sebuah protokol level aplikasi untuk kontrol atas pengiriman data dengan sifat real time, seperti audio dan video. RTSP sangat banyak digunakan oleh industri pengembang teknologi streaming media, hingga saat ini untuk media player pada handphone dan smartphone telah terintegrasi dengan protokol 
RTSP baik berbasis Java J2ME, Symbian maupun Android. Port default yang digunakan yaitu 544 [7].

\section{METODE PENELITIAN}

Prosedur penelitian yang terstruktur dapat membantu proses penyelesaian permasalahan yang dibahas pada penelitian ini. Prosedur yang digunakan dalam penelitian ini menggunakan metode pengembangan perangkat lunak System Development Life Cycle (SDLC), dengan model Waterfall. Berikut ini beberapa tahapan kegiatan yang lakukan.

1. Analisa Kebutuhan (Requirements Analysis)

Dalam tahap ini dilakukan dengan tahapan menganalisa permasalahan pada sistem yang sedang berjalan pada Universitas Catur Insan Cendekia untuk dapat menspesifikasikan kebutuhan perangkat lunak seperti apa yang dibutuhkan serta pengumpulan data-data yang diperlukan. Pada penelitian ini dilakukan wawancara terhadap Bagian Keamanan Universitas Catur Insan Cendekia, untuk mengetahui sistem yang sedang berjalan. Data yang dibutuhkan yaitu topologi seperti apa yang digunakan, serta perangkat keras apa saja yang digunakan.

2. Desain (Design)

Pada tahap ini dilakukan perancangan sistem yang akan dibangun, yang pertama yaitu melakukan konfigurasi pada aplikasi Shinobi untuk digunakan sebagai aplikasi bagian backend serta melakukan perancangan untuk pembuatan aplikasi bagian frontend. Hasil keluaran dari tahapan ini adalah perancangan sistem pada bagian frontend menggunakan UML yang meliputi Use Case Diagram, Activity Diagram, dan Sequence Diagram aplikasi monitoring keamanan ruangan pada Universitas Catur Insan Cendekia.

3. Pengkodean (Coding)

Pada tahap ini merupakan proses penerjemahan dari tahap perancangan ke dalam bentuk aplikasi, yaitu pembuatan aplikasi monitoring keamanan ruangan pada Universitas Catur Insan Cendekia.

4. Pengujian (Testing)
Pada proses ini masing-masing unit aplikasi monitoring keamanan ruangan pada Universitas Catur Insan Cendekia yang telah dibangun diintegrasikan, pada tahap ini dilakukan pengujian sistem menggunakan black box testing untuk menentukan aplikasi yang dirancang dapat digunakan atau tidak.

5. Pemeliharaan (Maintenance)

Jika aplikasi monitoring keamanan ruangan pada Universitas Catur Insan Cendekia yang diuji terdapat berbagai kesalahan maka dapat dilakukan perbaikan.

\section{HASIL DAN PEMBAHASAN}

Dari hasil wawancara kebutuhan yang dilakukan dengan Bagian Keamanan di Universitas Catur Insan Cendekia, dapat disimpulkan bahwa sistem keamanan yang digunakan pada Universitas Catur Insan Cendekia masih menggunakan CCTV analog yang terhubung dengan DVR sehingga kurang efektif karena harus memasuki ruangan yang terpasang DVR untuk mendapatkan informasi. Dapat dilihat pada gambar berikut ini.

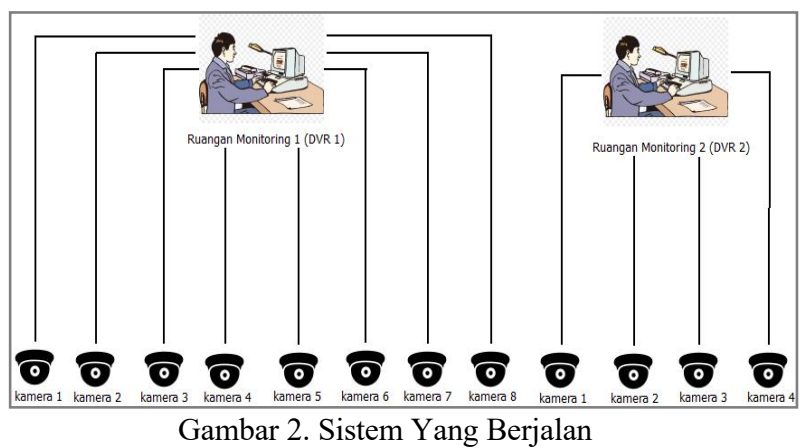

Dalam tahap analisis sistem dilakukan analisis terhadap kebutuhan perangkat keras untuk mengetahui perbandingan biaya antara menggunakan DVR dengan menggunakan sistem yang dibangun.

Tabel 1. Perbandingan Perangkat Keras

\begin{tabular}{|l|l|c|c|}
\hline CCTV DVR & \multicolumn{1}{|c|}{$\begin{array}{c}\text { Harga } \\
\text { Pasaran }\end{array}$} & Qty & \multicolumn{1}{c|}{ Total } \\
\hline $\begin{array}{l}\text { DVR } \\
\text { HIKVISION } \\
8 \text { Port }\end{array}$ & $\begin{array}{l}\text { Rp. } \\
800.000,-\end{array}$ & 1 unit & Rp. 800.000,- \\
\hline $\begin{array}{l}\text { Camera } \\
\text { HIKVISION }\end{array}$ & $\begin{array}{l}\text { Rp. } \\
200.000,-\end{array}$ & 8 unit & Rp.1.600.000,- \\
\hline Kabel & Rp. 9.000,- & 16 & Rp. 144.000,- \\
\hline
\end{tabular}




\begin{tabular}{|l|l|c|l|}
\hline Coaxial & \multicolumn{1}{|c|}{ meter } & \\
\hline $\begin{array}{l}\text { Connector } \\
\text { BNC }\end{array}$ & Rp. 10.000,- & 8 pcs & Rp. 80.000,- \\
\hline $\begin{array}{l}\text { Harddisk 500 } \\
\text { GB }\end{array}$ & $\begin{array}{l}\text { Rp. } \\
600.000,-\end{array}$ & 1 unit & Rp. 600.000,- \\
\hline Monitor & $\begin{array}{l}\text { Rp. } \\
500.000,-\end{array}$ & 1 unit & Rp. 500.000,- \\
\hline Total Biaya & \multicolumn{1}{|c|}{ Harga } & Qty & Total \\
\hline $\begin{array}{l}\text { Sistem yang } \\
\text { dibangun }\end{array}$ & \multicolumn{1}{|c|}{ Pasaran }
\end{tabular}

4 menunjukkan Activty Diagram Lihat Live Streaming.

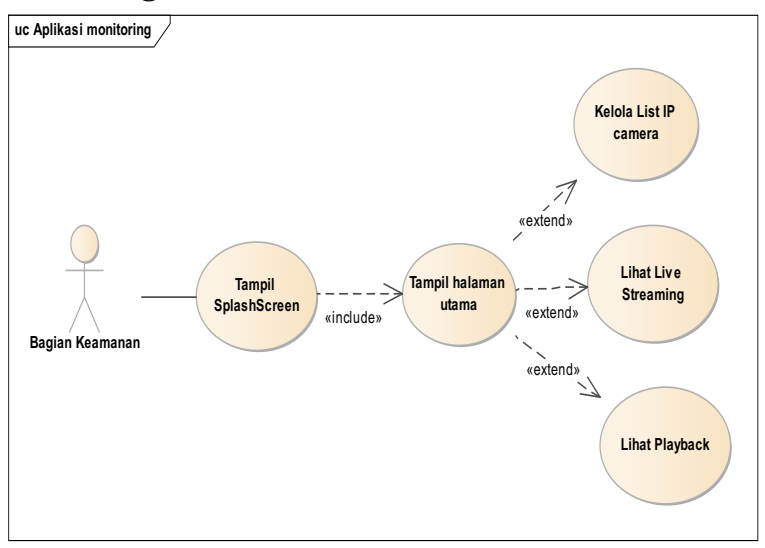

Gambar 3. Use Case Diagram

Dari tabel 1. dapat disimpulkan bahwa biaya perangkat keras dengan menggunakan sistem yang dibangun lebih murah daripada menggunakan CCTV DVR.

Hasil dari tahap perancangan yaitu melakukan konfigurasi pada aplikasi Shinobi. Download aplikasi Shinobi melalui link berikut ini http://Shinobi.video. Dalam link tersebut terdapat langkah-langkah konfigurasi aplikasi Shinobi.

Setelah melakukan konfigurasi terhadap aplikasi backend (aplikasi Shinobi) selanjutnya dilakukan perancangan sistem untuk aplikasi frontend (Android) yang dibangun. Berikuti ini hasil dari perancangan sistem pada aplikasi frontend.

\section{A. Use Case Diagram}

Use Case diagram, merupakan diagram yang digunakan untuk menggambarkan hubungan antara aktor dengan sistem. Diagram yang ditunjukkan pada gambar 3 hanya menggambarkan sistem secara global.

\section{B. Activity Diagram}

Activity diagram merupakan diagram yang digunakan untuk menggambarkan alur kerja (aktifitas) pada use case (proses), logika, proses bisnis serta menggambarkan hubungan antara aktor dan alur-alur kerja pada use case. Gambar

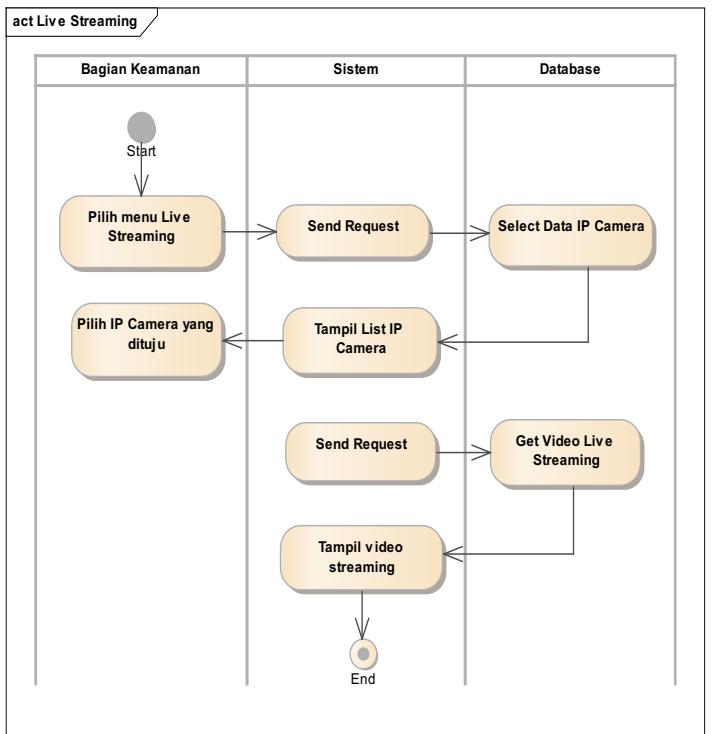

Gambar 4. Activity Diagram - Live Streaming

\section{Sequence Diagram}

Sequence diagram merupakan diagram yang disusun berdasarkan urutan waktu yang menjelaskan interaksi suatu objek. Berikut ini Sequence Diagram Lihat Playback. 
Jurnal Sistem Komputer dan Kecerdasan Buatan

Volume IV - Nomor 1 - September 2020

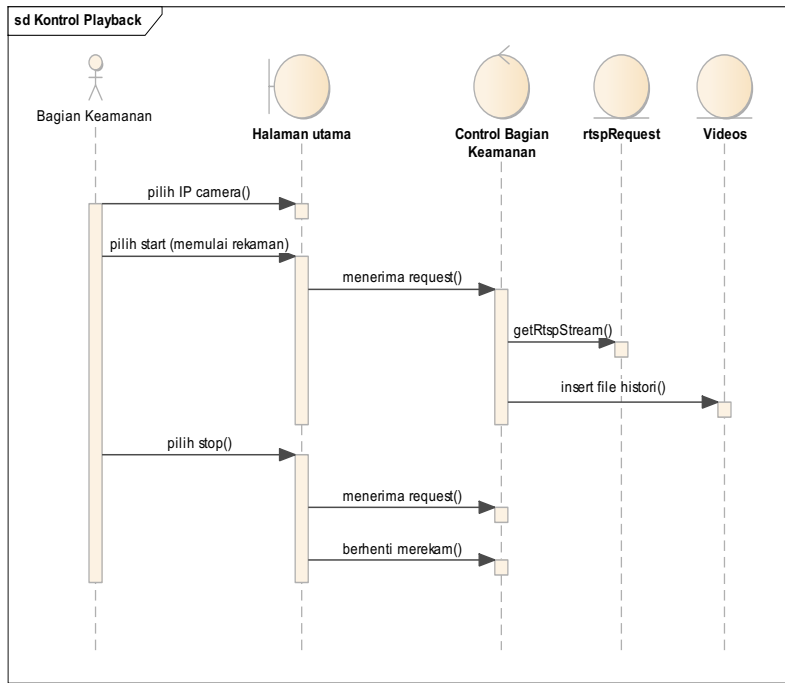

Gambar 4. Sequence Diagram - Lihat Playback

Implementasi merupakan hasil dari tahap perancangan kedalam bentuk aplikasi agar bisa digunakan. Berikut ini hasil implementasi dari aplikasi monitoring yang dibuat.

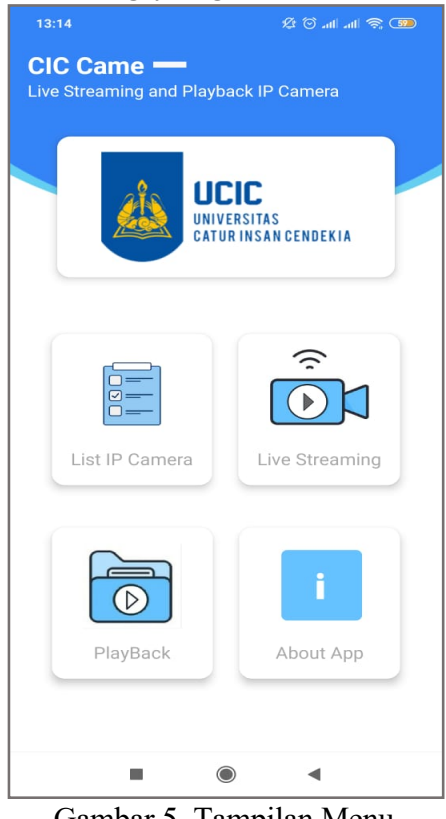

Gambar 5. Tampilan Menu

Tampilan menu merupakan form utama untuk memanggil form lainnya. Menu yang terdapat pada form utama ini yaitu: List IP Camera, berfungsi untuk mengelola data IP Camera seperti menambahkan,mengedit, atau menghapus data IP Camera. Live Streaming, berfungsi untuk melihat video streaming IP Camera. PlayBack, berfungsi untuk melihat histori rekaman IP Camera. About App, menampilkan deskripsi Aplikasi.

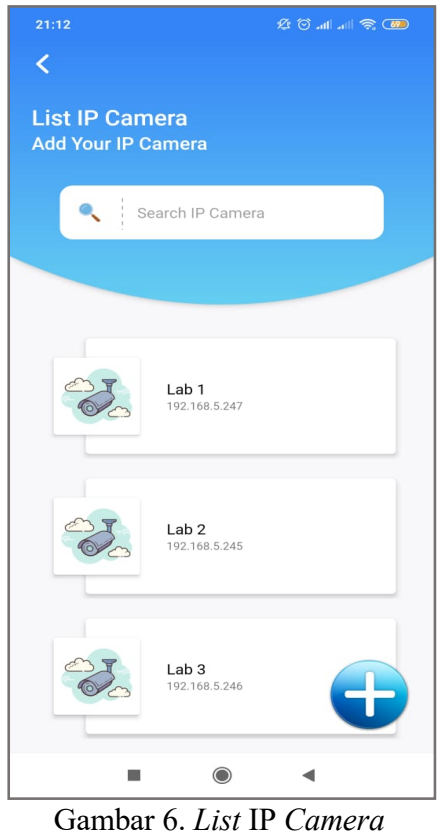

Pada form ini menampilkan data IP Camera yang telah di-input-kan, pada form ini juga terdapat menu + untuk menambahkan data $I P$ Camera baru.

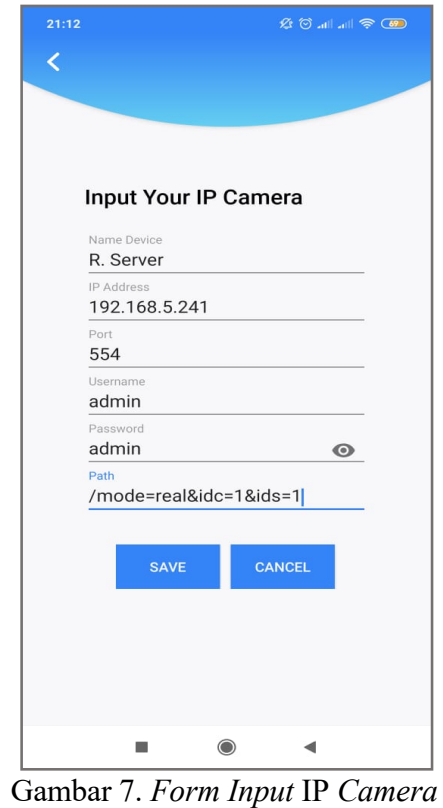

Form ini berfungsi untuk menambahkan data IP Camera, data-data yang di-input-kan yaitu Name device merupakan nama untuk IP Camera, IP address, port, username, password, dan path. 


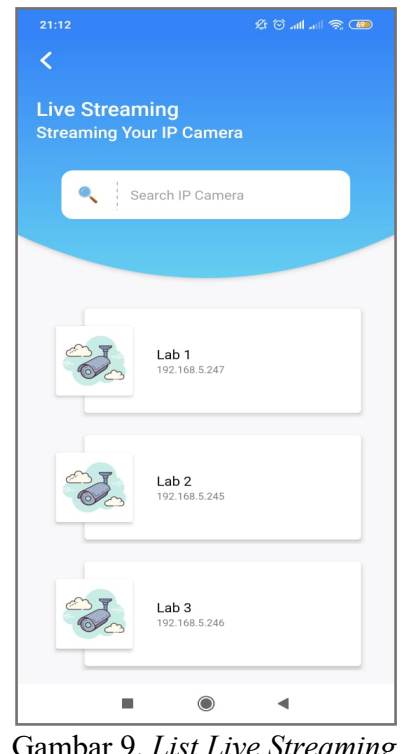

Pada form ini menampilkan list IP Camera yang telah di-input-kan sebelumnya, kemudian pilih IP Camera yang akan dilihat untuk video streaming. Kemudian akan menampilkan video streaming seperti gambar 10.

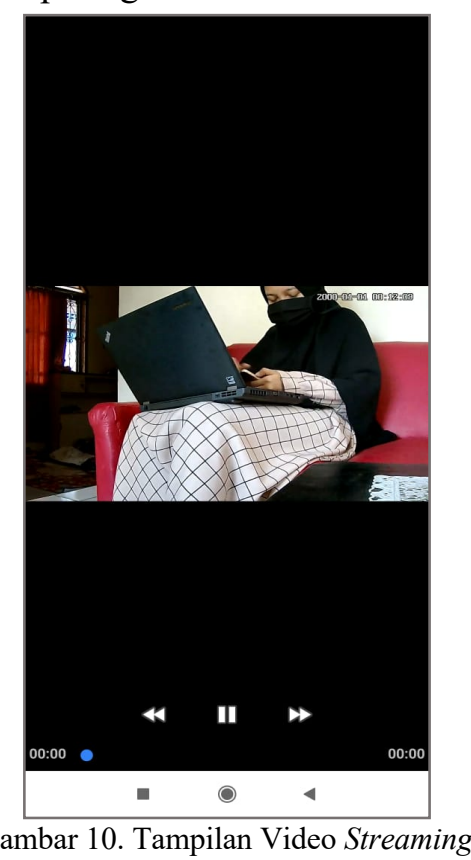

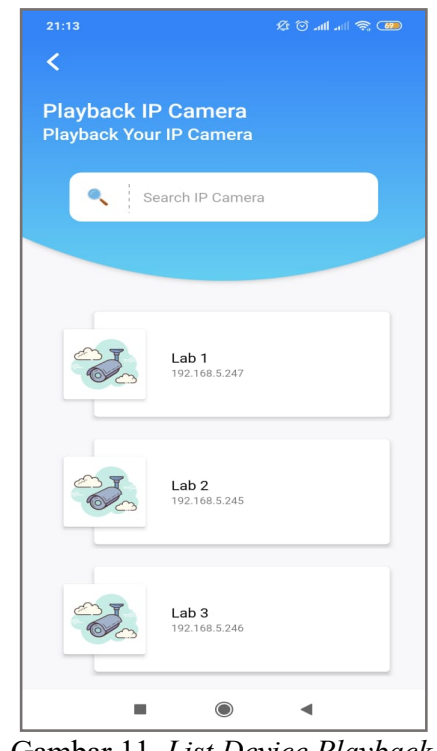

Gambar 11. List Device Playback

Pada form ini menampilkan data IP Camera yang sudah di-input-kan sebelumnya, kemudian pilih IP Camera yang akan dilihat historinya. Maka akan menampilkan daftar histori dari IP Camera yang dipilih, seperti gambar 12.

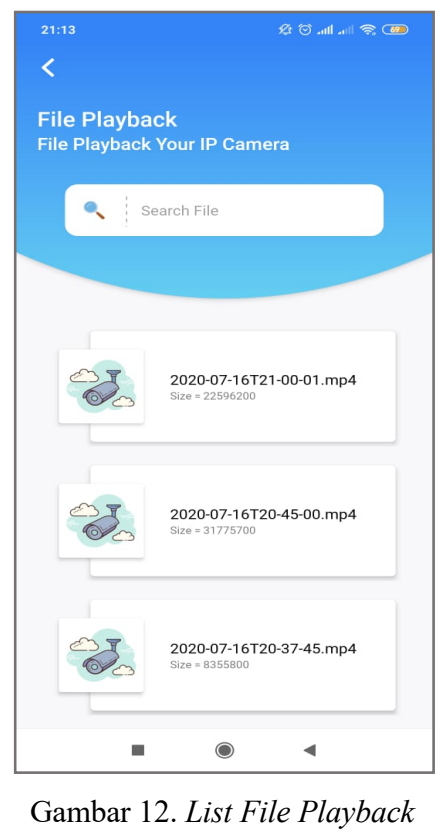

Form ini menampilkan data video histori rekaman berdasarkan IP Camera yang dipilih. Pilih video histori rekaman yang akan dilihat, maka akan menampilkan video histori rekaman seperti gambar 13. 


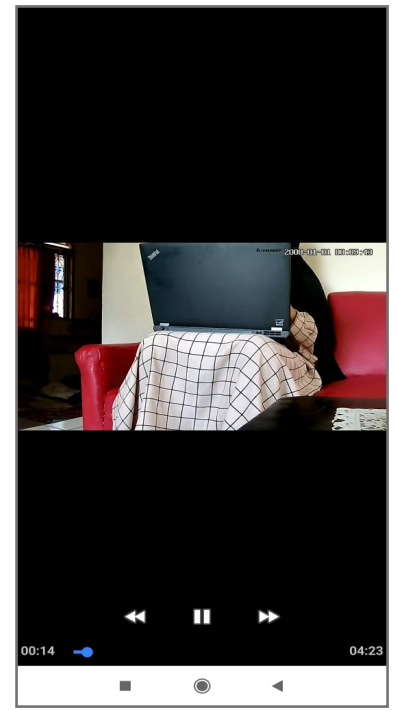

Gambar 13. Tampilan Video Playback

\section{SIMPULAN}

Berdasarkan hasil implementasi aplikasi monitoring ruangan berbasis Android, maka dapat disimpulkan sebagai berikut : Aplikasi ini dapat digunakan Bagian Keamanan dalam melakukan monitoring keamanan ruangan di sekitar Universitas Catur Insan Cendekia melalui smartphone Android. Keuntungan dari sistem ini adalah Bagian Keamanan dapat memonitoring keamanan ruangan dimanapun dan kapanpun jika dibandingkan dengan sistem lama (CCTV) yang terpusat dalam satu ruangan. Sehingga dengan adanya sistem ini dapat mempermudah Bagian Keamanan Universitas Catur Insan Cendekia dalam melaksanakan Work From Home (WFH).

\section{DAFTAR PUSTAKA}

[1] E. Fitriatun, "Perancangan Website Sistem Infomasi Monitoring Aktivtas Pemasaran Pada Pt. Pandowo Utomo Food Semarang," Peranc. Website Sist. Infomasi Monit. Akt. Pemasar. Pada Pt. Pandowo Utomo Food Semarang, vol. 53, no. 9, pp. 1689-1699, 2019, doi: 10.1017/CBO9781107415324.004.

[2] Fransica, "Application Programming Interface," 2019.

https://sis.binus.ac.id/2019/05/06/applicationprogramming-interface/.

[3] M. Bestari, "Rancangan Aplikasi Monitoring Kamera Cctv Untuk Perang' Kat Mobile Berbasis Android," Teknol. Inform. dan Komput., vol. 3, p. 46, 2016.

[4] E. Buulolo, "Aplikasi View Remote Camera Cetv Dengan Android Untuk Monitoring
Kegiatan Mahasiswa Dilaboratorium,”vol. VI, no. 1, pp. 1-4, 2017.

[5] S. Susilawati and M. Ashari, "Perancangan Jaringan Closed Circuit Television (CCTV) Berbasis Online Sebagai Monitoring Pada SDN 4 Praya," J. Manaj. Inform. dan Sist. Inf., vol. 1, no. 1, p. 11, 2018, doi: 10.36595/misi.v1i1.12.

[6] M. A. bin Amir, IP Camera dan Aplikasinya. Elex Media Komputindo, 2013.

[7] A. N. Rombe, L. F. Aksara, and L. Surimi, "Analisis Perbandingan Real Time Streaming Protocol (Rtsp) Dan Hypertext Transfer Protocol (Http) Pada Layanan Live Video Streaming," semanTIK, vol. 6, no. 1, pp. 91-96, 2019, doi: 10.5281/zenodo.3243704. 